\title{
Effect of Shock Therapies on Quality of Life
}

\section{Şok Tedavisinin Yaşam Kalitesine Etkisi}

Kıvanç YALIN

Uşak Üniversitesi Tıp Fakültesi, Kardiyoloji Anabilim Dalı, Uşak, Türkiye

The implantable cardioverter defibrillators (ICDs) are highly effective and life saving in the treatment of individuals who are at high risk of lethal ventricular arrhythmias and sudden cardiac death. Initially, ICDs were implanted to sudden death survivors for secondary prevention (1). After primary prevention trials (2-4), implantation of ICDs has become very common for patients who never experienced sudden cardiac death or hemodynamic compromise due to ventricular arrhythmias.

Despite ICDs reduce mortality for high risk individuals, many patients receive ICDs for insurance only, and many of them has never require ICD therapy during their life. In spite of being a life saving device, implantation of ICD brings out psychological disorders and social limitations to the recipients. ICD implantation has been shown to impact adversely on quality of life (QoL) and sporadic shocks were found to be associated with reduced QoL in ICD recipients (5-7).

My previous group studied depression and anxiety in Turkish ICD recipients and indicated presence of depression and anxiety in nearly half of the patients with ICD in 2006 (8). As ICD shocks reduces QoL and increases mortality, ICD programming strategies has been widely changed over ten years to reduce inappropriate shocks (9-10). And also prophylactic catheter ablation of ventricular arrhythmias causing ICD firing has been more often used (11).

After ten years of publication of depression and anxiety status study for Turkish patients, in this issue of Kocaeli Medical Journal, Dr. Bozyel and co-workers studied the effects of shock therapies on health related quality of life in 217 patients with ICDs (12). This study was performed in a new shock reducing programming and VT ablation era, and important with its national data on QoL. QoL analysis maybe affected by several factors and should be validated for each cohort and each nation.
In their study ICD shocks were associated with impaired health related QoL.

I think this study may light a way for future national ICD registries focusing on QoL analysis, and development of educational programs for ICD recipients on all possible risks and benefits, including transitory declines in QoL after ICD shocks in our country.

\section{REFERENCES}

1. Powell AC, Fuchs T, Finkelstein DM, et al. Influence of implantable cardioverter-defibrillators on the long-term prognosis of survivors of out-ofhospital cardiac arrest. Circulation 1993; 88:108392.

2. Bardy GH, Lee KL, Mark DB, et al. Sudden Cardiac Death in Heart Failure Trial (SCD-HeFT) Investigators. Amiodarone or an implantable cardioverter-defibrillator for congestive heart failure. N Engl J Med 2005; 352:225-37.

3. Moss AJ, Zareba W, Hall WJ, et al. Multicenter Automatic Defibril- lator Implantation Trial II Investigators. Prophylactic implantation of a defibrillator in patients with myocardial infarction and reduced ejection fraction. N Engl J Med 2002; 346:877-83.

4. Gold MR, Nisam S; Multicenter Automatic Defibrillator Implan- tation Trial, Multicenter Unsustained Tachycardia Trial. Primary prevention of sudden cardiac death with implantable cardioverter defibrillators: Lessons learned from MADIT and MUSTT. Pacing ClinElectrophysiol 2000; 23(11 Pt 2):1981-5.

5. Vlay SC, Olson LC, Fricchione GL, Friedman $\mathrm{R}$. Anxiety and anger in patients with ventricular tachyarrhythmias. Responses after automatic internal cardioverter defibrillator implantation. Pacing ClinElectrophysiol 1989; 12:366-73. 
6. Bainger EM, Fernsler JI. Perceived quality of life before and after implantation of an internal cardioverter defibrillator. Am J Crit Care 1995; 4:36-43.

7. Schron EB, Exner DV, Yao Q, et al.; and the AVID Investigators. Quality of life in the antiarrhythmics versus implantable defibril- lator trial: impact of therapy and influence of adverse symptoms and defibrillator shocks. Circulation 2002; 105:589-94.

8. Bilge AK, Ozben B, Demircan S, Cinar M, Yilmaz E, Adalet K. Depression and anxiety status of patients with implantable cardioverter defibrillator and precipitating factors. Pacing ClinElectrophysiol. 2006 Jun;29(6):619-26.

9. Poole JE, Johnson GW, Hellkamp AS, Anderson J, Callans DJ, Raitt MH, et al. Prognostic importance of defibrillator shocks in patients with heart failure. N Engl J Med. 2008;359:1009-17.

10. Daubert JP, Zareba W, Cannom DS, McNitt $\mathrm{S}$, Rosero SZ, Wang $\mathrm{P}$, et al. Inappropriate implantable cardioverter-defibrillator shocks in MADIT II: frequency, mechanisms, predictors, and survival impact. J Am Coll Cardiol. 2008;51:135765.

11. Influence of clinical and procedural predictors on ventricular tachycardia ablation outcomes: an analysis from the substrate mapping and ablation in Sinus Rhythm to Halt Ventricular Tachycardia Trial (SMASH-VT).

12. Bozyel S, AA Ayşen. The effect of shock therapies on health-related quality of life in patients with implantable cardioverter-defibrillator. Kocaeli Med J 2018; 7; 1:53-8. 